\title{
The Association Between Major Helminth Infections (Soil-Transmitted Helminthes and Schistosomiasis) and Anemia Among School Children in Shimbit Elementary School, Bahir Dar, Northwest Ethiopia
}

\author{
Abebe Getnet ${ }^{*}$, Seble Worku \\ Department of Medical Laboratory Technology, Bahir Dar Health Science College, Bahir Dar City, Ethiopia
}

Email address

abebegetnet55@yahoo.com (G. Abebe),workuseble@ymail.com (S. Worku)

To cite this article:

Abebe Getnet, Seble Worku. The Association Between Major Helminth Infections (Soil-Transmitted Helminthes and Schistosomiasis) and Anemia Among School Children in Shimbit Elementary School, Bahir Dar, Northwest Ethiopia. American Journal of Health Research. Vol. 3, No. 2, 2015, pp. 97-104. doi: 10.11648/j.ajhr.20150302.17

\begin{abstract}
Background: Helminthic infections contribute to iron-deficiency anemia among children in sub-Saharan Africa. Children and women of the reproductive age are particularly vulnerable to iron-deficiency anemia exacerbated by parasitic infection. Studies investigating magnitude of major helminthic infections and anemia and also their association are less in this study area. Hence, the present study was undertaken to assess the prevalence of major helminthic infections and anemia and also measure their association among school children. Methods: a cross-sectional parasitological and hematological study was conducted on 360 school children in Shimbit Elementary School, Bahir Dar, Northwest Ethiopia. Stool samples were collected and processed using Kato-Katz for microscopic examination. Blood sample was examined using Hemocue to determine the hemoglobin level. Some Socio-demographic and risk factor data were also collected from every study participant using structured questionnaire. Results: The overall prevalence of helminthic infection and anemia was $27.5 \%$ and $25.8 \%$, respectively. Ascaris lumbericiodes $12.5 \%$ and $960 \mathrm{epg}$, hookworms $7.2 \%$ and $102.5 \mathrm{epg}$, Trichuris trichiura $6.1 \%$ and 150 epg, Schstosoma mansoni $2.8 \%$ and $36 \mathrm{epg}, 0.5 \%$ of the children were positive for double infections (Ascaris lumbricoides and hookworm). Conclusion: Moderately high prevalence of helminthic infections and anemia was of moderate public health significance. Poor sanitary conditions were the major factors for helminthic infections and there was a strong association between anemia and presence of helminthes, especially with hookworm infections $(\mathrm{P}=0.00)$. Personal hygiene and good environmental sanitations is the mainstay to control helminthes infections.
\end{abstract}

Keywords: Anemia, Helminthes, School Children, Shimbit, Bahir Dar

\section{Background}

Globally, soil-transmitted helminthes (STH) and schistosome infections are among the major diseases of public health problems in tropical and subtropical countries [1]. Particularly, in children and pregnant women poses the greatest morbidity. Climatic factors with poor environmental, domestic and personal hygiene favor faeco-oral transmission of soil-transmitted helminthes in tropical and subtropical countries [2, 3].

Among 3.5 billion infected individuals found in the world, an estimated 400 millions are school-age children [4-6] and the infection is associated with stunting of linear growth, physical weakness, low educational achievement, intestinal obstruction, hepatic and bilary diseases and iron-deficiency anemia [7-10]. These are closely associated with low household income, poor personal and environmental sanitation and overcrowding, limited access to clean water, tropical climate and low altitude [11, 12]. Due to these reasons intestinal parasitic infections are widely distributed throughout the world, especially in tropical and sub tropical areas of the developing countries [13]. Infections with the major human gastrointestinal nematodes in Ethiopia are rampant and the prevalence of infections is variable from place to place and can be as high as 90\% [13].

Schistosomiasis has great public health importance next to 
malaria, with $>200$ million people infected in 74 countries of the world [14] among which 93\% occur in sub-Saharan Africa. This is so, because approximately $76 \%$ of the population in Sub Saharan Africa lives near different water bodies harboring snail intermediate hosts and contaminated with human excreta $[15,16]$. In Ethiopia large-scale agricultural use of rivers, the construction of highways and population movement lead to the spread of schistosomiasis [17].

Anemia is the most common manifestation of disease observed in the developing regions of the world. The highest incidence of anemia is reported in South Asia and subSaharan Africa, where a large proportion of women of reproductive age and preschool children are affected [18]. Iron-deficiency anemia affects about 1.3 billion people, with the highest prevalence and morbidity in young children and pregnant women [19]. It is estimated that up to half of school age children in developing countries are anemic [20,21].

In developing countries many causes of anemia have been identified, including deficiencies of micronutrients (e.g. iron, folate, and vitamin B12), haemoglobinopathies, infections and chronic diseases (e.g. malaria, NTDs, HIV, and TB) and cancer $[19,20,22,23]$. School-age children are particularly vulnerable to iron-deficiency anemia exacerbated by parasitic infection because they typically harbor the heaviest worm loads in communities [24]. World Health Organization has suggested that anemia is of "mild" public health importance where its prevalence is below 20\%, "moderate" public health importance where its prevalence is between $20 \%$ and $39.9 \%$ and "severe" if it occurs in $40 \%$ or more of the population [24].

In Ethiopia, the distribution and prevalence of soiltransmitted helminthiasis and schistosomiasis is relatively well understood [26] and vary from region to region because of several environmental, social and geographical factors. Several studies have been conducted on the distribution and prevalence of intestinal parasites [7], but, there are no studies that reveal the impact of intestinal parasitosis on anemia. Therefore, the purpose of the present study was to assess the association of schistosomiasis and soil-transmitted helminthes with anemia among schoolchildren in Shimbit Elementary School, Bahir Dar, Northwest Ethiopia.

\section{Methodology}

\subsection{Study Design, Period and Area}

Cross-sectional parasitological and hematological surveys were conducted to assess the prevalence of helmenthiasis and anemia and also risk factors on 360 children in Shimbit full cycle elementary school, Bahir Dar, $540 \mathrm{~km}$ far from Addis Ababa, the capital of Ethiopia in the North West direction, from December, 2009 to June, 2010.

\subsection{Study Participants}

Children selected, with a systematic random sampling technique from grade one to grade four using a quota system in each section for stool and blood examination from Shimbit full cycle elementary school, Bahir Dar.

\subsection{Sample Size and Sampling Procedures}

Sample size was calculated using single population proportion formula. By taking the prevalence of helminthiasis, $50 \%$, from other studies in other part of the country, $95 \%$ confidence interval and setting marginal error at 5\% and adding contingency of $5 \%$ a total of 360 sample size was calculated. Being public and nearby to Bahir Dar health science college was a factor in the selection of the school to be involved in the study. Four sections were selected from each grade and the number of students to be included from each grade was determined by quota system. A total of 360 students involved in the study were selected using a systematic sampling technique from school roster.

\subsection{Stool Sample Collection and Examination}

Each study participant was provided with clean, water proof and labelled plastic stool cup and applicator sticks to bring about two gram of fresh stool specimen. The collected samples were processed using Kato-Katz technique, (template delivering 41.7 milligram of stool) [27]. The prepared slides were kept in slide boxes and shipped within an hour to Bahir Dar Health Science College laboratory for examination. The slides were examined by experienced laboratory technologists.

\subsection{Blood Sample Collection and Examination}

Blood samples were collected from finger tip using disposable sterile lancets. Free drops of blood samples were filled in specialized micro-cuvettees by capillary action and placed in cuvettee holder of the photometer. Hemoglobin concentrations were measured using the Hemocue photometer (Hemocue, Laguna Hills, CA, HemoCue Hb 301) following the procedure described on hematology lecture note series for medical students [28].

\subsection{Socio-Demographic and Risk Factor Data Collection}

Socio-demographic data like age, sex and risk factors for the transmission of helminthic infections, such as wearing shoe, hand washing habit after toilet, parent's educational level, presence and proper utilization of latrine in homes, swimming, types of water source and nature of house floor were collected using structured questionnaire.

\subsection{Data Analysis and Interpretation}

Data were entered into a computer using Excel, checked for errors that might have occurred during data entry and analyzed using SPSS window (version 16.0) to generate descriptive statistics. Chi-squared $\left(\chi^{2}\right)$ tests were used to test for differences in prevalence of anemia and helminthiasis and with socio-demographic characteristics. P-values less than 0.05 were considered as statistically significant.

\subsection{Ethical Consideration}

The project obtained ethical clearance from Institutional Research Board (IRB) of Aklilu Lemma Institute of Pathobiology, Addis Ababa University, and Amhara National 
Regional State Health Bureau. In addition, verbal consent was obtained from school officials and parents or guardians of the children. Assent was also obtained from the children at the time of specimen collection. Study participants that tested positive for soil-transmitted helminthes and schistosomiasis were treated with albendazole (400mg, single dose) and praziquantel (40mg/kg, body weight), respectively.

\section{Results}

Of the total stool examined, 99/360 (27.5\%) of the children had single or double helmith infections while $261(72.5 \%)$ were free from any helminth. From ninety-nine children who had single or double helmithic infection, Ascaris lumbriciodes was found in 45 children who accounts $12.5 \%$ of the total helminthic infection with average 960 epg. Hookworms were found in 26 children (7.2\%) with average 102.5 epg. Trichuris trichiura was found in $22(6.1 \%)$ with average 150 epg. Schstosoma mansoni was found in 10 children $(2.8 \%)$ of the total helminthic infection with average $36 \mathrm{epg}$ and only two $(0.5 \%)$ children were positive for double infections (Ascaris lumbricoides and hookworms). Among 99 children positive for helminthes, 59(59.6\%) were males and 40(40.4\%) females with a male to female ratio of 1:0.7 (Table 1). The prevalence seems to be higher in males but it had no statistically significant difference $(\mathrm{P}>0.311)$. With the exception of hookworms the prevalence of parasites is higher in males than females (Fig 1). The prevalence of helminth infections were higher in the lower age group, 52.5\% in 7-9 years age group, $36.4 \%$ in $10-14$ years age group and $11.1 \%$ in the elderly age group (Table 1), but there is no statistically significant difference in infections among the age groups $(\mathrm{P}>0.44)$.

Table 1. Prevalence of helminth infections by age groups and gender among school children in Shmbit Elementary School, Bahir Dar, Northwest Ethiopia, 2010

\begin{tabular}{|c|c|c|c|c|}
\hline \multirow{2}{*}{ Age group(years) } & \multicolumn{2}{|c|}{ Number $(\%)$ of children examined } & \multicolumn{2}{|c|}{ Number $(\%)$ of children positive for helminthes } \\
\hline & male & Female & male & Female \\
\hline $7-9$ & $96(26.7)$ & $75(20.8)$ & $30(8.3)$ & $22(6.1)$ \\
\hline $10-14$ & $79(21.9)$ & $60(16.6)$ & $22(6.1)$ & $14(3.9)$ \\
\hline $15-18$ & $24(6.7)$ & $26(7.2)$ & $7(1.9)$ & $4(1.1)$ \\
\hline Total & $199(55.3)$ & $161(44.7)$ & $59(59.6)$ & $40(40.4)$ \\
\hline
\end{tabular}

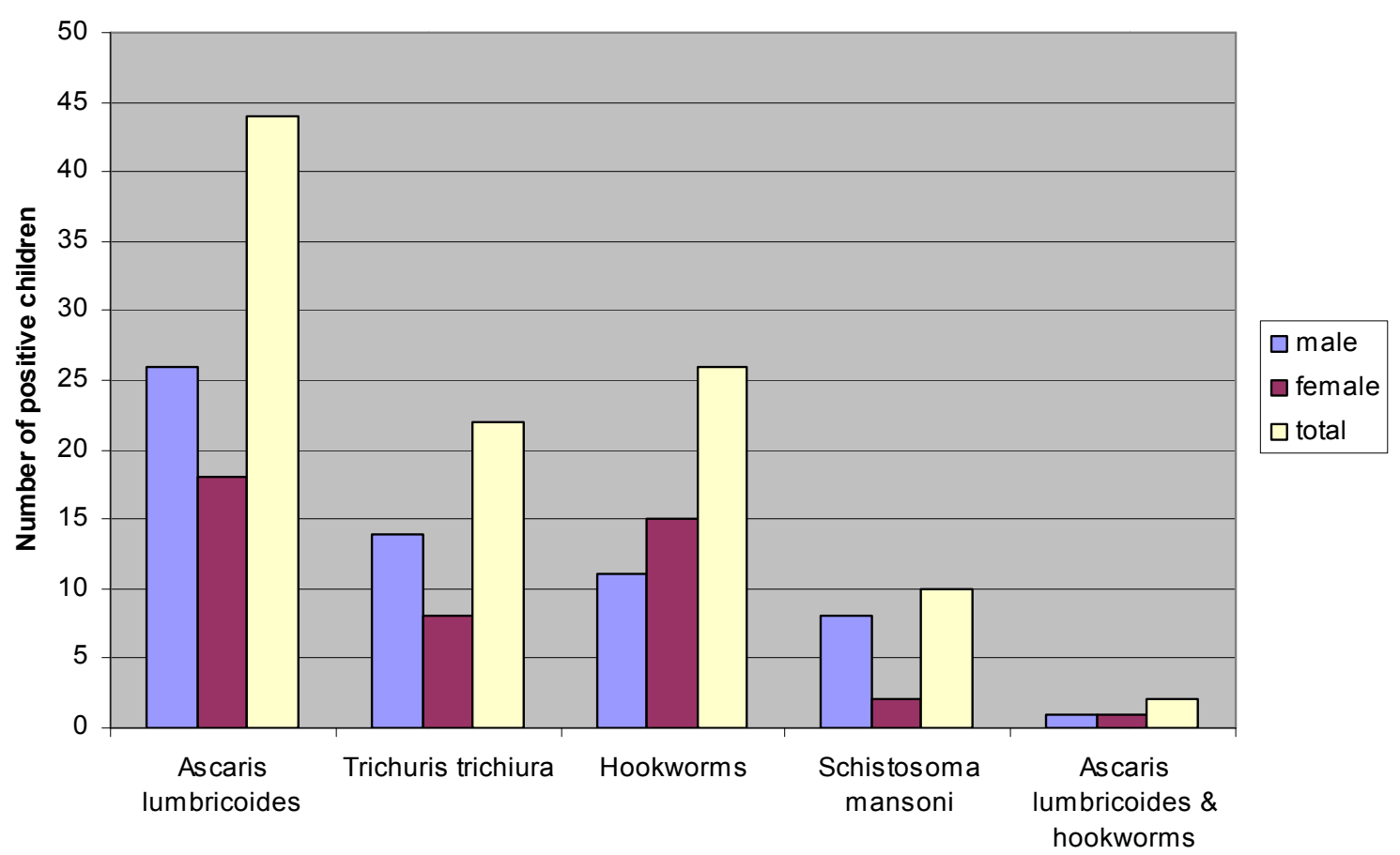

Types of parasites found

Figure 1. Distribution of helminth species by gender in Shimbit Elementary School, Bahir Dar, Northwest Ethiopia, 2010.

According to WHO infection intensity classification [29], Ninety-five $(96 \%)$ out of the ninety nine helminth-infected children had light-intensity helminthic infections. Of the forty-five $A$. lumbricoides infections, forty-four were of lightly infected $(<5,000 \mathrm{epg})$, one was of moderately infected (5,000-49,999 epg), and there was no heavy infection( $\geq 50,000 \mathrm{epg}$ ). Among twenty two children who had trichuriasis twenty-one children had light intensity of infection $(<1000$ epg) and only one children had moderate intensity of infection (1000-9999) and there was no heavy intensity of infection $(\geq 10,000 \mathrm{epg})$. Of the twenty-six hookworm infections, only one was of moderate intensity of infection (2,000-3,999 epg); the rest were light-intensity of infections $(<2,000 \mathrm{epg})$. No one presented with a heavy 
hookworm infection ( $\geq 4,000$ epg). Only one of the ten children with schistosomiasis had moderate intensity of infection with detectable ova count of 144 epg and there was no heavy intensity of infection ( $>400 \mathrm{epg}$ ). In this study poly parasitized children were not common except two children infected by two parasites (Ascaris lumbricoides and hookworms) and also no heavy intensity of infections except few moderate ones were seen.

The risk factors attributed to the transmission of soiltransmitted helminthes and schistosomiasis were assessed and shown in Table 2. At the time of sample collection almost all of the children $(95.4 \%)$ wore at least sandal shoes and $4.6 \%$ were bare footed. Although, most of the children had shoe wearing habit, they did not use regularly for example they taken off their shoes during play and when they are around their home even go to latrine. Bare footed children were found to be affected by helminth infections than those with shoes $(\mathrm{P}<0.027)$.

More than two-thirds, $315(87.5 \%)$ of the children reported having a latrine or toilet in the household, and 45 (12.5\%) had no toilet or latrine. There is a strong association between helminth infection and the absence of latrine or toilet $(\mathrm{P}<0.0001)$. Only about one-fourth of the children $90(25 \%)$ responded to have hand washing habit after toilet and before meal. Those children who had no hand washing habit were affected by parasitic infection than those who had hand washing habit $(\mathrm{P}<0.006)$. About $90 \%$ of the children lived in houses with soil floor but, the nature of the floor had no direct correlation with the prevalence of helminth infection $(\mathrm{P}>0.05)$.

Almost all of the children obtained their water supply from protected sources like pipeline and protected springs. Parent's educational level was assessed and prevalence of helminth infections in children decreased as parent's educational level increased $(\mathrm{P}<0.0001)$ (Table 3$)$. Swimming habits were seen in elderly children, mostly boys aged greater than 15 years than girls of any age group $(\mathrm{p}<0.02)$ and Schistosoma mansoni infection was predominant in 15-18 years age group than the lower two age groups [(7-9) and 10-14)] years $(\mathrm{P}<0.027)$.

Table 2. Risk factors for heliminth infections among children in Shimbit Elementary School, Bahir Dar, Northwest Ethiopia, 2010.

\begin{tabular}{|c|c|c|}
\hline Risk factors & Categories & Number (\%) \\
\hline \multirow{5}{*}{ Parent education level } & illiterate & $62(17.2 \%)$ \\
\hline & read and write & $106(29.4 \%)$ \\
\hline & $1-6$ & $110(30.6 \%)$ \\
\hline & $7-12$ & $52(14.4 \%)$ \\
\hline & $12+$ & $30(8.3 \%)$ \\
\hline \multirow{2}{*}{ Latrine } & Present & $315(87.5 \%)$ \\
\hline & Absent & $45(12.5 \%)$ \\
\hline Hand washing & No & $270(75.0 \%)$ \\
\hline \multirow{3}{*}{ Water source } & Pipeline & $300(83.3 \%)$ \\
\hline & protected spring/well & $59(16.4 \%)$ \\
\hline & lake/river & $1(0.3 \%)$ \\
\hline \multirow{2}{*}{ Shoe wearing } & Yes & $339(94.2 \%)$ \\
\hline & No & $21(5.7 \%)$ \\
\hline Swimming & Yes & $31(8.6 \%)$ \\
\hline \multirow{2}{*}{ Floor type } & Cement & $82(22.8 \%)$ \\
\hline & Soil & $278(77.2 \%)$ \\
\hline Total & & $360(100.0 \%)$ \\
\hline
\end{tabular}

Table 3. Helminth infections by parent's educational level in Shimbit Elementry School, Bahir Dar, Northwest Ethiopia, 2010.

\begin{tabular}{llll}
\hline & Category & Number (\%) of children examined & Number (\%) of children positive for helminthes \\
\hline & Illiterate & $62(100.0 \%)$ & $25(40.3)$ \\
& read and write & $106(100.0 \%)$ & $37(34.9 \%)$ \\
Parent's educational level & Grade 1-6 & $110(100.0 \%)$ & $27(24.5 \%)$ \\
& Grade 7-12 & $52(100.0 \%)$ & $8(15.4 \%)$ \\
& Grade 12+ & $30(100.0 \%)$ & $2(6.7 \%)$ \\
Total & & $360(100.0 \%)$ & $99(27.5 \%)$ \\
\hline
\end{tabular}

Among three hundred sixty children from whom blood samples were collected, anemia was detected from ninetythree $(25.8 \%)$ children (Table 5) with mean hemoglobin value of $13.5 \mathrm{mg} / \mathrm{dl}$ (range $6.8-15.2 \mathrm{~g} / \mathrm{dl}$ ). According to WHO, anemia was defined as hemoglobin less than $11 \mathrm{~g} / \mathrm{dl}$ for children under six years old, less than $12 \mathrm{~g} / \mathrm{dl}$ for children both gender between six and fourteen years of age and female older than fifteen years of age and below $13 \mathrm{~g} / \mathrm{dl}$ in males older than fifteen years of age. The highest prevalence of anemia (81/93 [87.1\%]) was observed among children infected with helminthes than uninfected children $(12 / 93$ [12.9\%]) $(\mathrm{P}<0.0001)$ (Table 4). Prevalence of anemia was high in the age between seven and nine $(55.9 \%)$ followed by age group ten-to-fourteen $(28.0 \%)$ and fifteen-to-eighteen 
(16.1\%), and there is statistically significant difference among age groups $(\mathrm{P}<0.0001)$.

Table 4. Anemia among school children with and without helminth infectionsin Shimbit Elementary School, Bahir Dar, Northwest Ethiopia, 2010.

\begin{tabular}{lllll}
\hline & & Stool test result & & \multirow{2}{*}{ Total } \\
\cline { 3 - 4 } & & Positive (\%) & Negative (\%) & \\
\hline \multirow{2}{*}{$\mathrm{Hb}$ level } & Anemic $(\mathrm{Hb}<12 \mathrm{~g} / \mathrm{dl})$ & $81(87.1 \%)$ & $12(12.9 \%)$ & $93(100.0 \%)$ \\
Total & Non-anemic $(\mathrm{Hb} 212 \mathrm{~g} / \mathrm{dl})$ & $18(7.1 \%)$ & $259(92.9 \%)$ & $255(100.0 \%)$ \\
\hline
\end{tabular}

Table 5. Distribution of anemia in different age groups among school children in Shimbit Elementary School, Bahir Dar, Northwest Ethiopia, 2010.

\begin{tabular}{lll}
\hline Age group (yrs) & No(\%)of children examined & No (\%)of children with anemia \\
\hline $7-9$ & $171(47.5 \%)$ & $52(55.9 \%)$ \\
$10-14$ & $139(38.6 \%)$ & $26(28.0 \%)$ \\
$15-18$ & $50(13.9 \%)$ & $15(16.1 \%)$ \\
Total & $360(100 \%)$ & $93(100 \%)$ \\
\hline
\end{tabular}

\section{Discussion}

Epidemiological surveys of schistosomiasis and soiltransmitted helminth infections and anemia among school children in different areas have been used to identify highrisk communities because school age children are an important segment of the population affected by helminth infections [4-6] and to formulate appropriate intervention. The present study was also conducted to determine the prevalence of schistosomiasis and soil-transmitted helminthiasis and anemia among school children in Shimbit full cycle elementary school, Bahir Dar, Northwest Ethiopia. The results showed the occurrence of schistosomiasis and soil-transmitted helminthes which are of public health importance and the presence of association of helminthiasis with anemia.

The overall prevalence of soil-transmitted helminth infections and schistosomiasis was observed to be $27.5 \%$. The prevalence observed in the present study was lower than the prevalence reported in some other parts of Ethiopia [7, 30]. This is due to difference in study population and parasites ecology.

In the present study, prevalence of helminth infections was higher among children in the age group 7-9 years and decreased with age. This is similar with study from southern and central zone of Tigray [17] and among rural Indian school going children [9]. The decline of infection with rise in age is due to children's behavior, that is, younger children are more exposed to faecally contaminated soil, since they usually play in the open fields and eat food without washing hands.

In Ethiopia, the national prevalence of hookworms, Ascaris lumbricoides, and Trichuris trichiura infections were $16 \%, 37 \%, 30 \%$, respectively [31]. In this study the respective prevalence of Ascaris lumbriciodes, hookworms and Trichuris trichiura were $12.5 \%, 7.2 \%$ and $6.1 \%$. The findings cannot be compared with the national figure due to the fact that, the national one covers the whole population and area of the county and taking the average prevalence of these helminths ranging from minimum to $90 \%$ [13] while our study was under taken in a small village around Bahir Dar town.
Hookworm infection is acquired through contact with contaminated soil [32] and most of the time bare footed individuals are at high risk of infection. However, in the present study hookworm infection was not significantly associated with bare footed children. This finding agreed with the result obtained in Babile school children that difference in hookworm infection between those with and without shoes was not statistically significant [8].

The prevalence of intestinal Schistosomiasis was $2.8 \%$ and this prevalence was high in children having contact with water source in rivers or lake and boys elder than fifteen years. These groups (boys elder than fifteen years and those use water from river/lake) are at high risk of contracting schistosomiasis because they have frequent contact with water during swimming and fetching. Further studies are required to confirm whether or not transmission of schistosomiasis takes place at water contact point during swimming or fetching.

Globally, Ascaris lumbricoides, Trichuris trichiura, and hookworms are the most prevalent parasites, with hookworm being more common than T. trichiura [33]. This distribution of soil-transmitted helminth infections being consistent with various studies [34] but in the present study the frequency of helminth infections is high for Ascaris lumbricoides followed by hookworms.

The overall prevalence of anemia was $25.8 \%$ among school children in Shimbit Elementary School, Bahir Dar, Northwest Ethiopia. This was similar to the prevalence of anemia in Aracaju Sergipe, Brazil primary school children (26.7\%) [34] Rural North Gaza (25\%) [21] and rural Vietnam (25\%) [35]. WHO categorized severity of anemia into three classes, as mild $(\mathrm{Hb}=11.9-9.0 \mathrm{~g} / \mathrm{dl})$, moderate $(\mathrm{Hb}=8.9$ $7.0 \mathrm{~g} / \mathrm{dl}$ ) and severe ( $\mathrm{Hb}$ below $7.0 \mathrm{~g} / \mathrm{dl}$ ) [36]. Based on this classification, $88.2 \%$ of anemia was mild, $9.7 \%$ moderate and $2.2 \%$ severe.

Hookworms are the leading cause of anemia and malnutrition than any other species of parasites, particularly among children and women of child-bearing age in developing countries [24, 37, 38], but in this study it was observed that a single infection with $A$. lumbericoides, $T$. thrichiura, hookworms or $S$. mansoni even at low to moderate intensities were found to be associated with anemia. 
This may be due to the confounding effect of poor nutritional status of study participants.

In rural Vietnam, reported that anemia is prevalent in youngest group of school children and boys are more anemic than girls [35]. This report is similar with present finding in that anemia was predominantly higher in young children (7-9 years) and in males than females. This has similarity in the age group and differences in sexes in Aracaju Sergipe, Brazil primary school [34]. This is so because; this age group harbored the highest prevalence of helminth infection in our study. In addition, these children require the greatest physiological demands for iron during growth and are at the highest risk of iron deficiency anemia.

The present study showed strong association between hookworm infections and anemia even at low intensity of infection. This agreed with the report from Philippines, that hookworm alone at the low intensity associated with elevated odds of anemia [39], in Zanzibari, intestinal blood loss and iron deficiency anemia were strongly related to hookworm egg counts [24] and in Madhya Pradesh, were mean hemoglobin value was significantly lower in hookworm infected than those in non-infected [40]. On the contrary, other studies have shown that presence of hookworm infection did not significantly associate with low hemoglobin value $[7,23,35,41]$. This might be explained by poor nutritional status of the school children or by differences in the species of hookworm [37].

Since, educational level of head of the house hold is one of the health indicators of children health [42], association between parent's educational level and prevalence of helminth infections was assessed. The finding showed that, there was an inverse relationship between parent's educational level and prevalence of helminth infections. This result agreed with report in a western city sample-Turkey that the prevalence of intestinal parasites was higher in groups where the mother in the household had less than a primary school education [11].

In Népal, reported that, the prevalence of parasitic infection was predominantly higher among girls than boys in rural school adolescent children. The reasons mentioned for the increased prevalence of parasitic infection in females than males was due to difference in the family preferences for their bringing up. Almost all the opportunities are preferentially given to male children (learning, playing, and other facilities). On the other hand, in many rural areas, girls are not enrolled in school and their job at home is to look after their younger siblings, help cooking and to look and support their mothers in house hold works [43]. This report has no consistence with the present study because, girls and boys have equal chances of schooling, playing and also the prevalence of helminth infections have no significant difference among male and female children.

Non-hygienic living conditions give rise to parasitic infections in children. On the other hand, personal hygiene (like hand washing) and environmental sanitation (like appropriate use of latrine) are a key determinants for the prevention of intestinal parasitic infections. This concept was reflected in this study that children who had hand washing habit after toilet and before meal were less likely to be affected by parasitic infections. Similarly, the presence of toilet or latrine was also an important factor for reducing parasitic infection; those children who had no latrine in their home affected more by parasitic infection.

\section{Conclusion and Recommendations}

The present study revealed that the observed prevalence of helminth infections and anemia was of moderate public health importance among school children in Shimbit Elementary School, Bahir Dar, Northwest Ethiopia. Helminth infections contributed to the prevalence of anemia. Although the prevalence of helminth infection in Shimbit Elementary School was lower compared to other parts of the country, there is a need for intervention programs because all the parasites identified had strong association with anemia.

High prevalence of intestinal parasitic infections is closely correlated with poverty indicators such as poor environmental sanitation, lack of safe water supply, contamination of the environment by human excreta, lack of shoes, and poor nutrition.

The risk factors for the transmission of helminth infections among study children in Shimbit Elementary School were described and almost all the factors had direct relationship with prevalence of helminth infection and anemia. This information enables the school health and control programs to be implemented.

Based on the major findings of the study, the following recommendations were made. To decrease the prevalence of helminth infections and anemia and impact of helminth infections on anemia among children in Shimbit Elementary School, it is recommended to establish appropriate intervention and control measures. These measures should include periodic deworming of the children with appropriate anthelminth agents, improve nutritional status of the family, providing school base health education such as the use of shoe wearing, trimming nails, improve house hold incomes, improving environmental sanitation by construction of latrine and improve personal hygiene by supplying sufficient water, providing hand washing equipments.

Finally, detailed studies are required to obtain clear association between helminth infections, anemia and association between helminth infections and anemia, nutritional status and anthropometry of the children.

\section{Acknowledgements}

We would like to thank gratefully shimbit elementary school children, teachers, administrative staff, without them, we would have not been able to bring our work to a successful completion. I would like to express my gratitude to Addis Ababa University, Aklilu Lemma institute of pathobiology and Amhara Regional State Health Bureau for their financial support. Special thanks would be forwarded for Bahir Dar Health Science College, department of Medical 
Laboratory Technology for the assistance of laboratory analysis.

\section{References}

[1] Cooper PJ, Chico ME, Vaca MG, Moncayo AL, Bland JM, Mafl E, Sanchez F, Rodrigues LC, Strachan DP and Griffi GE. 2006. Effect of albendazole treatments on the prevalence of atopy in children living in communities' endemic for geohelminth parasites: a cluster-randomised trial. Lancet 367:1598-1603.

[2] Wani SA, Ahmad F, Zargar SA, Fomda BA, Ahmad Z and Ahmad P. 2007. Helminthicinfestation in children of Kupwara district: A prospective study. Indian Journal of Medical Microbiology 25:398-400.

[3] Levecke B, De Wilde N, Vandenhoute E and Vercruysse J. 2009. Field validity and feasibility of four techniques for the detection of Trichuris trichiuria in simians. Public Library of Science Tropical Neglected Diseases 3:e366.

[4] Alfonso J, Morales R, Barbella RA, Case C, Arria M, Ravelo M, Perez H, Urdaneta O, Gervasio G, Rubio N, Maldonado A, Aguilera Y, Viloria A, Blanco JJ, Colina M, Hern'andez E, Araujo E, Cabaniel G, Benitez J, and Rifakis P. 2006. Intestinal parasitic infection among pregnant women in Venzuela. Infectious Disease in Obstetrics and Gynecology 23125:1-5.

[5] Escobedo AA, Cañete R and Núñez FA. 2008. Prevalence, risk factors and clinical features associated with intestinal parasitic infections in children from San Juany Martínez, Pinar del Río, Cuba. West Indian Medical Journal 57:377-382.

[6] Cook DM, Swanson RC, Eggett DL and Booth GM. 2009. A retrospective analysis of prevalence of gastrointestinal parasites among school children in the Palajunoj valley of Guatemala. Journal of Health population and Nutrition 27:3140.

[7] Legesse $M$ and Erko B. 2004. Prevalence of intestinal parasites among schoolchildren in a rural area close to the southeast of Lake Langano, Ethiopia. Ethiopian Journal of Health Development 18:116-120.

[8] Tadesse G. 2005.The prevalence of intestinal helminthic infections and associated risk factors among school children in Babile town, eastern Ethiopia. Ethiopian Journal of Health Development 19:140-147.

[9] Dongre AR, Deshmukh PR, Boratne AV, Thaware P and Garg BS. 2007. An approach to hygiene education among rural Indian school going children. Online Journal of Health Allied Sciences 4:1-6.

[10] Goodman D, Haji HJ, Bickle QD, Stoltzfus RJ, Tielsch JM,Ramsan M, Savioli L and Albonico M. 2007. A comparison of methods for detecting the eggs of Ascaris, Trichuris, and hookworm in infant stool, and the epidemiology of infection in Zanzibari infants. American Journal of Tropical Medicine and Hygiene 76:725-731.

[11] Okyay P, Ertug S, Gultekin B, Onen O and Beser E.2004. Intestinal parasites prevalence and related factors in school children, a western city sample-Turkey. BioMed Central Public Health 4:64-70.
[12] Mengistu A, Gebre-silasie S and Kassa T. 2007. Prevalence of intestinal parasitic infection among urban dwellers in southwest Ethiopia. Ethiopian Journal of Health Development 21:12-17.

[13] Teklemariam Z, Abebe G and Mullu A. 2008. Opportunistic and other intestinal parasitic infections in AIDS patients, HIV sero-positive healthy carriers and HIV sero-negative individuals in southwest Ethiopia. East African Journal of Public Health 5:169-173.

[14] Ross AGP, Bartley PB, Sleigh AS, Olds GR, Li Y, Williams GM and McManus DP. 2002. Schistosomiasis. New England Journal of Medicine 346:1212-1220.

[15] Gryseels B, Polman K, Clerinx J and Kestens L. 2006. Human schistosomiasis. Lancet 368:1106-1118.

[16] Hotez PJ, Kamath A. 2009. Neglected tropical diseases in Sub-Saharan Africa: Review of their prevalence, distribution and disease burden. Public Library of Science Neglected Tropical Diseases 3:e412.

[17] Dejenie T and Petros B. 2009. Irrigation practices and intestinal helminth infections in southern and central zones of Tigray. Ethiopian Journal of Health Development 23:48-56.

[18] Tatala S, Svanberg U and Mduma B. 1998. Low dietary iron availability is a major cause of anemia: A nutrition survey in the Lindi district of Tanzania. The American Journal of Clinical Nutrition 68:171-178.

[19] Dreyfuss ML, Stoltfus RJ, Shrestha JB, Predhan EK, Le Clerg SC, Katz J, Albonico M and West KP. 2000. Hookworms, malaria and vitamin A deficiency contribute to anemia and iron deficiency among pregnant in the plain of Nepal. Journal of Nutrition 130:2527-2536.

[20] Bates A, Mckew S and Sarkinfada F. 2007. Anemia: A useful indicator of neglected disease burden and control. Public Library of Science Medicine 4:e231.

[21] Al-zain BF. 2009. Impact of socioeconomic conditions and parasitic infection on hemoglobin level among children in Um-Unnasser village, Gaza Strip. Turkish Journal Medical Science 39:53-58.

[22] Erosie L, Merid Y, Ashiko A, Aynie M, Belihu A, Muzeyin S, Teklemariam S and Sorsa S. 2002. Prevalence of hookworm infection and haemoglobin status among rural elementary school children in southern Ethiopia. Ethiopian Journal of Health Development 16:113-115.

[23] Hung LQ, de Vries P, Giao PT, Binh TQ, Nam NV and Kager PA. 2005. Anemia, malaria and hookworm infections in a Vietnamese ethnic minority. South East Asian Tropical Medicine and Public Health 36:206-211.

[24] Stoltzfus J, Chwaya HM, Tielsch JM, Schulze KJ, Albonico M, Savioli L. 1997.Epidemiology of iron deficiency anemia in Zanzibari school children: The importance of hookworms. American Journal of Clinical Nutrition 65:153- 159.

[25] Pasricha SR, Caruana SR, Phuc TQ, Casey GJ, Jolley M, Kingslan dS, Tien NT, MacGregor L, Montresor A and Biggs BA. 2008. Anaemia, Iron Deficiency, Meat Consumption and Hookworm Infection in Women of Reproductive Age in Northwest Vietnam. American Journal of Tropical Medicine and Hygiene 78:375-381. 
[26] Wodimagegnehu T, Birrie $\mathrm{H}$ and Yeneneh H. 1997. Schistosomiasis and intestinal helminthic infections in Delo Awraja, Bale administrative region south Ethiopia. Ethiopian Journal of Health Development 13:183-188.

[27] World Health Organization 1991. Basic laboratory methods in medical parasitology. Parasitology Laboratory Manuals 92:2528.

[28] Sahlemariam Z. 2003. Hemocue method. Hematology for Medical Laboratory Students Lecture Note Series. First Edition. Carter Printing Press. Addis Ababa. 73-76.

[29] World Health Organization 2002. Prevention and control of schistosomiasis and soil transmitted helminthiasis. WHO Technical Report Series 912:1-57.

[30] Mengistu A, Gebre-silasie S and Kassa T. 2007. Prevalence of intestinal parasitic infection among urban dwellers in southwest Ethiopia. Ethiopian Journal ofHealth Development 21:12-17.

[31] Tadesse Z, Hailemariam A and Kolaczinski JH. 2008. Potential for integrated control of neglected tropical diseases in Ethiopia. Transactions of the Royal Society of Tropical Medicine and Hygiene 102, 213-214.

[32] Hotez PJ, Brooker S, Bethony JM, Bottazzi ME, Loukas Aand Xiao S. 2004.Hookworminfection. New England Journal of Medicine 351:799-807.

[33] Warren KS, Bundy DAP, Anderson RM, Davis AR, Henderson DA, Jamison DT, Prescott N and Senft A. 1993. Helminth infection. In: Disease Control Priorities in Developing Country (D. T. Jamison; W. H. Mosley; A. R. Measham \& J. L. Bobadilla, eds.), pp. 131-160, Oxford: Oxford University Press.

[34] Tsuyuoka R, Bailey JW, Alzira M, Guimarães DN, Gurgel RQ and Cuevas LE. 1999. Anemia and intestinal parasitic infections in primary school students in Aracaju, Sergipe, Brazil. Cadernos De Saude Publica Rio De Janeiro15:413-421.

[35] Thi Le H, Brouwer ID, Verhoef H, Nguyen KC and Kok FJ. 2007. Anemia and intestinal parasite infection in school children in rural Vietnam. Asia Pacific Journal of Clinical Nutrition 16:716-723.

[36] WHO/UNICEF/UNU 2001. Iron Deficiency Anemia: Assessment, Prevention, and Control. A Guide for Program managers. WHO/NHD/01.3.

[37] Saeed A, Cheema HA, Alvi A and suleman H. 2008. Hookworm infestations in children presenting melana-case series. Pakistan Journal of Medicine 47:1-3.

[38] Griffiths GD, Brown AB, Hooi DSW, Pearce PC, Hornby RJ, Scott L and Pritchard DI.2009. Development of a model of hookworm infection exhibiting salient characteristics of human infection. American Journal of Tropical Medicine and Hygiene 78: 936-945.

[39] Ezeamama AE, McGarvey ST, Acosta LP, Zierler S, Manalo DL, Wu HW, Kurtis JD, Mor V, Olveda RM and Friedman JF. 2008. The synergistic effect of concomitant Schistosomiasis, Hookworm, and Trichuris infections on Children's anemia burden. Public Library of Science Neglected Tropical Diseases $4: \mathrm{e} 245$.

[40] Rao VG,Aggrawal MC,Yadav R, Das SK, Sahare LK, Bondley MK, Minocha RK. 2003. Intestinal parasitic infections, anemia and under nutrition among tribal adolescents of Madhya Pradesh. Indian Journal of Community Medicine 28:1-3.

[41] Mupfasoni D, Karibushi B, Koukounari A, Ruberanziza E, Kaberuka T, Kramer KH, Mukabayire O, Kabera M,Nizeyimana Y, Deville MA, Ruxin J, Webster JP and Fenwick A. 2009. Polyparasite helminth infections and their association to anemia and under nutrition in Northern Rwanda. Public Library of Science Neglected Tropical Diseases 3: e517.

[42] Hacettepe University Institute of Population Studies, 1998. Turkish Demographic Health Survey (TDHS) Ankara.

[43] Rijal B, Oda Y, Basnet R, Parajuli K, Gurung CK and Sherchand JB. 2001. Gender variation in the prevalence of parasitic infection and level of awareness in adolescents in rural Nepal. American Journal of Tropical Medicine and Hygiene 32:575-580. 